\title{
Concepções de docentes sobre o uso de metodologias ativas da aprendizagem: Um enfoque na formação de enfermeiros
}

\author{
Gesica Kelly da Silva Oliveira \\ Enfermeira. Especialista em Urgência e Emergência. Especialista em Ginecologia e Obstetrícia. \\ Mestra em Educação em Ciências e Matemática UFPE-CAA. \\ Preceptora de Estágios do Curso de Enfermagem do Centro Universitário \\ do Vale do Ipojuca - UNIFAVIP|Wyden \\ $\triangle$ gesicakelly.oliveira@gmail.com
}

\section{Kátia Calligaris Rodrigues}

Docente da Universidade Federal de Pernambuco - UFPE. Pós-doutorado desenvolvido junto ao Núcleo de Excelência em Nanofotônica e Biofotônica do Laboratório de Optoeletrônica e Fotônica do Departamento de Física da UFPE. Doutora em Engenharia Biomédica pela Universidade do Vale do Paraíba. Mestre em Ciências pela Universidade de São Paulo. Bacharel e Licenciada em Física pela Universidade Presbiteriana Mackenzie e Licenciada em Pedagogia pela Universidade Federal de São Carlos

$\square$ kalligaris@gmail.com

\section{Maria Aparecida de Oliveira Freitas}

Docente do Quadro Permanente do Programa de Pós-Graduação Ensino em Ciências da Saúde do Centro de Desenvolvimento do Ensino Superior em Saúde - CEDESS/UNIFESP. Pós-Doutorado na área de Formação

Docente em Saúde para o Ensino Superior e Interprofissionalidade. Doutorado em Ciências pela UNIFESP. Mestrado em Ensino em Ciências da Saúde pela UNIFESP. Especialização em Educação em Saúde pela UNIFESP. Graduação em Pedagogia pela Universidade Augusto Motta

Maofreitas@unifesp.br

\begin{abstract}
Resumo:
As vertiginosas mudanças na conjuntura social têm posto em reflexão, de maneira contundente, os aspectos relacionados a formação profissional em enfermagem. Assim, esta discussão surge mediante a necessidade de considerar os fatores que são próprios do trabalho em saúde, tais como a relação intrínseca entre as atividades práticas e a teoria, o cuidado holístico, crítico e humanizado, visto que estes elementos são essenciais para o apropriado exercício profissional. Este trabalho objetivou investigar a percepção dos docentes do curso de graduação em enfermagem sobre a utilização e contribuição das metodologias ativas da aprendizagem no processo de formação e desenvolvimento do profissional enfermeiro. Trata-se de um estudo de natureza qualitativa de caráter exploratóriodescritivo, que foi realizado com docentes de um Centro Universitário do Agreste Pernambucano. Os dados foram coletados por meio de entrevista semiestruturada, para apreciação dos dados obtidos foi realizada análise de conteúdo, seguindo o referencial teórico proposto por Minayo. Os resultados demonstraram que os docentes compreendem a relevância das metodologias ativas para a formação em enfermagem, entretanto evidenciamos não haver um planejamento de um ensino ativo, pelo professor, demonstrando afinidade com a transmissão de conteúdo, o que sinaliza a importância da atitude reflexiva constante no campo da docência em enfermagem.

Palavras-chave: Educação Superior, Educação em Enfermagem, Enfermagem, Aprendizagem Ativa.
\end{abstract}




\title{
Concepts of teachers on the use of active learning methodologies: An approach to nursing training
}

\begin{abstract}
:
The vertiginous changes in the social conjuncture have put in a forceful reflection, the aspects related to professional training in nursing. Thus, this discussion arises through the need to consider the factors that are proper to health work, such as the intrinsic relationship between practical activities and theory, holistic, critical and humanized care, since these elements are essential for the appropriate professional practice. This work aimed to investigate the perception of undergraduate nursing teachers about a form of use and one of the active learning methodologies in the process of training and development of the nurse professional. This is a qualitative study of an exploratory nature, which was carried out with professors from the University Center of Agreste Pernambucano. The data were collected through a semi-structured interview, to analyze the data, a content analysis was performed, following the theoretical framework proposed by Minayo. The results showed that teachers understand one of the active methodologies for nursing education, but they show that there is no active teaching process, by the teacher, demonstrating affinity with a content transmission, which signals the importance of the reflexive attitude of the teaching field in nursing.

Keywords: Higher Education, Education Nursing, Nursing, Active Learning.
\end{abstract}

\section{Conceptos de docentes sobre el uso de metodologías activas del aprendizaje: Un enfoque en la formación de enfermeros}

\section{Resumen:}

Los vertiginosos cambios en la coyuntura social han puesto en reflexión, de manera contundente, los aspectos relacionados a la formación profesional en enfermería. Así, esta discusión surge mediante la necesidad de considerar los factores que son propios del trabajo en salud, tales como la relación intrínseca entre las actividades prácticas y la teoría, el cuidado holístico, crítico y humanizado, ya que estos elementos son esenciales para el apropiado ejercicio profesional. Este trabajo objetivó investigar la percepción de los docentes de curso de graduación en enfermería sobre una forma de utilización y de una de las metodologías activas de aprendizaje en el proceso de formación y desarrollo del profesional enfermero. Se trata de un estudio de naturaleza cualitativa de carácter exploratorio, que fue realizado con docentes del Centro Universitario del Agreste Pernambucano. Los datos fueron recolectados por medio de una entrevista semiestructurada, para el análisis de los datos se realizó un análisis de contenido, siguiendo el referencial teórico propuesto por Minayo. Los resultados demostraron que los docentes comprenden una de las metodologías activas para la formación en enfermería, pero evidencian que no hay un proceso de enseñanza activa, por el profesor, demostrando afinidad con una transmisión de contenidos, lo que señala la importancia de la actitud reflexiva campo de la docencia en enfermería.

Palabras clave: Educación Superior, Educación en Enfermería, Enfermería, Aprendizaje Activo.

\section{INTRODUÇÃO}

A Educação superior no Brasil vem enfrentando diversas mudanças, em decorrência das necessidades sociais, estas, por sua vez, são fundamentais na formação superior em saúde, uma vez que estes profissionais exercem suas atividades em um âmbito complexo (ABREU, 2014). 
Para Ceccim e Feuerwerker (2004) é importante que haja uma reestruturação na educação superior em saúde que contemple uma formação acadêmico- científica, onde o profissional trabalhe a integralidade do indivíduo, a ética, o perfil humanitário, a reflexividade e a gestão em saúde.

Nesta vertente, as instituições de Ensino Superior vêm buscando mudanças no projeto político-pedagógico de forma que englobe tais características preconizadas pelas Diretrizes Curriculares Nacionais (DCN). Portanto, é imprescindível que proponham um processo de ensino-aprendizagem pautado pelo envolvimento dos sujeitos e pelo estímulo ao pensamento crítico-reflexivo que constitui um ponto de vista mediador entre ensino e ação (LUCCHESE, VERA e PEREIRA, 2010).

As Diretrizes Curriculares Nacionais para o curso de graduação em enfermagem ressaltam que a estrutura do curso deve assegurar, entre outras demandas "a implementação de metodologia no processo ensinar-aprender que estimule o aluno a refletir sobre a realidade social e aprenda a aprender" (BRASIL, 2001 p.5). Neste sentido, a formação do profissional enfermeiro, deve contemplar estratégias variadas de ensino-aprendizagem que instiguem a autonomia discente e o processo de tomada de decisão em saúde, uma vez que estas permeiam cotidianamente a vida deste profissional (BERBEL, 2011; MELO et al., 2014).

Tais características apresentadas nas DCN inerentes a esta profissão, vêm acompanhadas de outros atributos essenciais, uma vez que estes profissionais trabalham com seres humanos e para seres humanos, deste modo, a reflexividade das ações, a resolutividade, o espírito de equipe, a liderança, a sensibilidade de enxergar o outro de forma holística, entre outras aptidões que devem ser estimuladas e desenvolvidas durante o processo de formação (LUCCHESE,VERA e PEREIRA, 2010).

Assim, é importante investigar as práticas docentes, bem como suas concepções sobre metodologias ativas da aprendizagem, uma vez que a aplicabilidade dessas metodologias podem contribuir na e para a formação de um profissional ético, mais humano, com saber científico adequado, reflexivo e capaz de transformar com seu conhecimento o contexto no qual está inserido (MENEGAZ, 2012; PARANHOS e MENDES, 2010). 
Indagar sobre a formação dos profissionais de enfermagem implica em conhecer as competências inerentes a essa profissão, os ambientes complexos que os profissionais estão inseridos e suas metodologias de trabalho, que estão pautadas no cuidar. Esses questionamentos devem permear não só a prática docente como também às instituições formadoras, para que analisem suas práticas cotidianas, na perspectiva de propiciar uma formação crítica, reflexiva, de qualidade e, por conseguinte uma assistência por excelência, fundamentada em um perfil profissional científico, ético, humanístico e transformador de sua prática (LIBÂNEO, 2009).

Nesta perspectiva, este trabalho objetivou investigar a percepção dos docentes de um curso de graduação em enfermagem sobre a utilização e contribuição das metodologias ativas da aprendizagem no processo de formação e desenvolvimento do profissional enfermeiro.

\section{METODOLOGIA}

Trata-se de estudo de natureza qualitativa realizado com docentes de um curso de Enfermagem de um Centro Universitário, localizado no agreste Pernambucano.

Para coleta de dados foi realizada uma entrevista semiestruturada, sendo que este tipo de entrevista se caracteriza por conter questões norteadoras que funcionam como um guia para a coleta dos dados pretendidos, permitindo serem realizados outros questionamentos que admitam atingir o objetivo proposto (MESQUITA, 2012).

A amostra foi do tipo não probabilística, o número de participantes foi determinado pela saturação dos dados. Assim, 07 docentes foram entrevistados, seguindo os seguintes critérios: possuir formação pedagógica em nível de graduação ou pós-graduação, lecionar no curso de enfermagem, possuir mestrado ou título acadêmico superior.

O registro das entrevistas foi realizado com utilização de gravação das falas dos participantes, com posterior transcrição na íntegra. Os dados coletados nas entrevistas foram submetidos à análise de conteúdo considerando o referencial teórico de Minayo, sendo constituído de três etapas: pré-análise; exploração do material; tratamento dos resultados, inferência e interpretação (MINAYO, 2001). 
Este trabalho foi submetido à Plataforma Brasil para avaliação do Comitê de Ética em Pesquisa (CEP), tendo em vista a análise acerca das questões éticas envolvidas no mesmo. Tal processo avaliativo teve por base a Resolução nº 466/2012 do Conselho Nacional de Saúde. Após aprovação do projeto pelo CEP do Centro Universitário do Vale do Ipojuca, sob Certificado de Apresentação para Apreciação Ética (CAAE) de nº 60868816.0.0000.5666 e parecer consubstanciado de aprovação do CEP de $n^{\circ}$ 1.773.628, executados dados foram coletados.

A coleta dos dados aconteceu durante o mês de fevereiro de 2017. No período que antecedeu a coleta, foi entregue um convite impresso aos participantes, com informações referentes aos objetivos da pesquisa, métodos, riscos e benefícios. Antes de iniciar a coleta de dados, todos os participantes foram informados sobre a assinatura do TCLE - Termo de Consentimento Livre e Esclarecido como condição para participação desta pesquisa e sobre os benefícios que os resultados obtidos trarão para toda a sociedade.

Durante a realização do estudo propriamente dito, tanto a privacidade quanto o sigilo dos dados obtidos de maneira primária e secundária foram garantidos resguardando-se quaisquer possíveis constrangimentos aos indivíduos pesquisados.

No intuito de manter o sigilo e o anonimato das informações, os participantes foram codificados pela ordem de participação, com a letra D de Docente e o número correspondente à ordem em que foram realizadas as entrevistas: D1, D2, D3, D4, D5, D6, D7.

\section{RESULTADOS E DISCUSSÃO}

Participaram desta pesquisa 07 docentes do curso de enfermagem que contemplaram os critérios de inclusão declarados. O quadro 1 sumariza a caracterização dos participantes, de acordo com as variáveis: ordem de participação, sexo, formação e tempo de experiência na docência. 
Quadro 1 - Caracterização dos Participantes da Entrevista. Caruaru, PE, Brasil, 2018.

\begin{tabular}{|c|c|c|c|}
\hline Participante & Sexo & $\begin{array}{l}\text { Formação } \\
\text { Acadêmica }\end{array}$ & $\begin{array}{c}\text { Tempo de Experiência na } \\
\text { docência }\end{array}$ \\
\hline D1 & Feminino & Enfermagem & Entre 4 a 7 anos \\
\hline D2 & Masculino & Enfermagem & Entre 4 a 7 anos \\
\hline D3 & Feminino & Enfermagem & Entre 1 a 3 anos \\
\hline D4 & Feminino & Enfermagem & Entre 8 a 10 anos \\
\hline D5 & Masculino & Ciências Biológicas & Entre 4 à 7 anos \\
\hline D6 & Feminino & Enfermagem & Entre 4 a 7 anos \\
\hline D7 & Feminino & Enfermagem & Entre 1 a 3 anos \\
\hline
\end{tabular}

Fonte: OLIVEIRA; RODRIGUES E FREITAS, 2017.

Observamos a predominância feminina na docência universitária do curso de enfermagem, dado que corrobora a inserção histórica da mulher no trabalho docente (GODINHO et al., 2015). No que concerne formação acadêmica dos entrevistados, mostrou-se predominante, neste recorte, a formação em enfermagem. A pesquisa mostrou que a maioria dos participantes possui mais de 04 anos de experiência e de acordo com Gil (2017), a partir de 4 anos de experiência na docência, o professor possui estabilidade profissional, melhor relacionamento com os discentes, domina estratégias e instrumentos, bem como lida de forma mais eficiente com situações complexas e imprevisíveis. 
As falas proferidas pelos docentes nos conduziram a dividir a análise em três categorias: 1) Protagonismo do Discente no Processo de Aprendizagem; 2) As Estratégias de Ensino e sua Utilização no Processo de Aprendizagem; 3) Estratégias de Aprendizagem e Percepções sobre a Prática.

\section{$1^{\mathrm{a}}$ Categoria: Protagonismo do Discente no Processo de Aprendizagem}

Ensinar é um processo de partilha que envolve uma sequência intencional de atividades e atitudes a serem executadas por docentes e discentes. Este processo nos obriga a refletir na forma como concebemos o conhecimento e a aprendizagem (FERNÁNDEZ, 2001; FREIRE, 2006; LIBÂNEO, 2009).

Aprender, além da responsabilidade e mobilização para construir os saberes, exige o estabelecimento de relações do sujeito consigo, com o mundo e com o outro. Mediante o estabelecimento de tais relações, o discente desenvolve concepções de mundo e de como transformá-lo, cuja aprendizagem, alicerçada em uma perspectiva de autonomia e próatividade, abrange dimensões cognitivas mais duradoras e significativas (CHARLOT, 2000; MITRE et al., 2008).

A prática docente não pode desconsiderar o contexto que envolve a articulação entre conhecimento e mundo e deve ser pautada pela ótica educacional dialógica, onde a teoria e a prática se vinculam no intuito de dar sentido ao que se aprende e propiciar uma consciência sobre a responsabilidade social de cada um (CHARLOT, 2000; FERNANDEZ, 2001; BERBEL, 2011).

Os docentes participantes desta pesquisa acreditam que as metodologias ativas de ensino e aprendizagem são importantes na construção do conhecimento. Os depoimentos apontam a preocupação com a criticidade e reflexividade na formação profissional, bem como no protagonismo dos discentes inseridos neste processo.

As falas transcritas abaixo revelam a compreensão dos docentes acerca da importância das Metodologias Ativas da Aprendizagem - MAA no contexto do processo de ensinar e aprender no curso de graduação em enfermagem: 
“[...] Se eu não trabalhar de forma ativa, inserindo esse aluno no conteúdo, gerando essa responsabilidade, reconstruindo esse conceito de como se aprende, se eu não botar o aluno para ser seu protagonista, eu acho que o professor não consegue fazer muita coisa, eu acho que a gente pode mascarar realmente esse processo de estar ensinando (D1).

"Um dos focos dessa metodologia ativa é buscar no aluno a sua visão crítica, então a partir do momento em que você coloca o aluno participante desse processo de ensino e aprendizagem, em que ele possa trocar suas ideias com o professor, que ele possa dar a sua opinião crítica sobre o assunto eu acredito que isso é positivo para o aprendizado dele (D2)".

“[...] Então, metodologias ativas faz com que o ensino desloque o eixo do docente e aquele estudante passe a ser uma parte importantíssima, indispensável para o processo, a ideia de metodologias ativas eu entendo que é fazer com que quem está envolvido no processo não seja passivo, ou seja, proponha, critique, reflita, diga não, diga eu discordo [...]" (D3).

"Dá ao aluno a oportunidade de ser o principal ator da aprendizagem, e é isso o que faz ele se estimular e querer estudar mais, ele perceber que ele é capaz de aprender (D5)".

Nas falas apresentadas acima, a autonomia no desenvolvimento do intelecto e a reflexividade dos conteúdos aprendidos, são pontuadas como fundamentais para o desenvolvimento da aprendizagem, demonstrando que a maioria dos docentes entrevistados parece ter um entendimento pertinente da temática discutida neste item.

De acordo com Severo e Kasseboehmer (2017) a autonomia está relacionada ao desejo de aprender, aprender porque o discente quer, porque entende que é importante e não por uma simples obrigação. Para os mesmos autores, o professor deve exercer um caráter motivacional à aprendizagem, sendo um promotor da autonomia, incentivando, despertando curiosidade, promovendo o engajamento, autoconfiança e a autorregulação.

No que concerne a reflexividade, observamos nas falas acima que 2 dos docentes entrevistados acreditam que a utilização de MAA estimulam, além da autonomia, o desenvolvimento do pensamento reflexivo. Segundo Leitão (2007) refletir é reconsiderar as nossas ações, ou seja, realizar a autorregulação do pensamento, considerando as concepções de mundo de cada indivíduo, o objeto de conhecimento e as limitações e bases que o ancoram.

A profissão do enfermeiro envolve constantemente a tomada de decisão, pois estes profissionais atuam em ambientes complexos, composto por vários atores e condicionantes que fazem parte do processo saúde-doença. Neste contexto, a formação em saúde 
(considerando a aprendizagem numa perspectiva transformadora) não pode acontecer fora deste âmbito reflexivo, onde ainda na academia, o futuro profissional, pensa sobre seu objeto de estudo, suas ações (tomada de decisão), entraves e a partir destas constrói e ressignifica o conhecimento (ABREU, 2014).

Assim, o processo de ensino e aprendizagem que privilegia o aluno como centro desse processo deve contemplar a mediação e a corresponsabilidade, em contraposição ao ensino tradicional, tecnicista, acrítico e centrado no docente como detentor do conhecimento. Nesta perspectiva do aluno como elaborador do próprio conhecimento, situa o professor como mediador do processo. Esta parceria entre docente e estudante deverá estar baseada no engajamento, especialmente dos estudantes, na autonomia e na reflexão proporcionando assim, significado aos saberes aprendidos na formação em enfermagem.

Pelas falas proferidas pelos docentes, podemos observar que os professores, consideram que as MAA, estão alicerçadas em uma visão progressista de ensino, onde este não está condicionado à transmissão do conhecimento, mas à sua construção, partilha e significação:

\footnotetext{
"Eu acredito que as metodologias ativas elas vieram realmente para mudar esse parâmetro do professor ser o dominante na sala de aula, elas fazem com que o aluno ele também possa estar exercitando esse seu lado mais crítico, mais reflexivo relacionado a determinado assunto" (D2).
}

\begin{abstract}
"As Metodologias Ativas deslocam o eixo da aprendizagem do professor, que a luz da educação tradicional detinha todo conhecimento, e em uma perspectiva progressista de educação eu diria que até humanitária, o professor não detém todo conhecimento como tem muito que aprender com as experiências prévias dos estudantes" (D3).
\end{abstract}

"Então é mais proveitoso, digamos assim, do que a gente só achar que está depositando conhecimento em alguém" (D7).

Os participantes desta pesquisa entendem que a centralidade do processo de ensino e aprendizagem deve ser no discente, cabendo ao docente, não o papel de protagonista, detentor de todo conhecimento, mas de mediador e regulador das situações de aprendizagem. 
Para Souza, Sartorib e Roesler (2008) a mediação situa o docente como incentivador da aprendizagem e são as atitudes desse profissional, que quando pautadas pelo diálogo, troca de experiências, problematização e dialética, promovem a construção dos saberes.

Outro aspecto importante observado na pesquisa foi a utilização de métodos diversificados de ensino, considerando que os indivíduos aprendem em diferentes modos e tempos:

\begin{abstract}
"É importantíssimo está se utilizando de metodologias, as mais variadas possíveis até para torrnar o ambiente diferente, porque tem aluno que se adequa em aprender de um modo, já tem aluno que possui maior facilidade em aprender de outra forma, então é aquela coisa, o professor como modulador ele precisa se utilizar de diversas estratégias, de diversas ferramentas para conseguir contemplar a forma de conhecimento dos diversos tipos de alunos, tanto na seleção da estratégia de ensino, quanto avaliação da aprendizagem" (D4).
\end{abstract}

Evidenciamos a percepção pertinente do docente no que se refere ao respeito à individualidade dos discentes, quando é colocada a diversidade dos estudantes na sala de aula, a importância dos espaços de aprendizagem diferentes, e a necessidade de estratégias de ensino e avaliação que contemplem tais especificidades neste campo de atuação.

Neste sentido, a utilização das metodologias ativas da aprendizagem na formação em enfermagem, contempla esta dinâmica de comprometimento com o aprender, bem como, com as características de cada sujeito (MELO et al., 2014). Ainda de acordo com Melo e seus colaboradores, as MAA associadas a uma postura ativa dos docentes e discentes, impulsionam a aprendizagem, uma vez que ambos são instigados a sair da "zona de conforto", construindo conhecimentos sólidos, por meio das experiências prévias, da problematização, do confronto com a realidade, engajamento e tomada de decisão.

\title{
2 ${ }^{\text {a }}$ Categoria: As Estratégias de Ensino e sua utilização no Processo de Aprendizagem
}

Anastasiou e Alves (2005) indicam que as diversificações das estratégias de ensinagem promovem uma superação ao ensino tradicional que apresenta a aula expositiva como instrumento único de exposição dos conteúdos. Este modelo de ensino quando utilizado de forma hegemônica em sala de aula, parece não contemplar, de forma efetiva, o contexto que envolve a construção dos conhecimentos, promovendo na maioria das vezes a memorização, a fragmentação dos conteúdos e a aprendizagem sem apropriação. 
Para as autoras, a seleção das estratégias de ensino deve considerar as dimensões do processo de ensino e aprendizagem, que envolve: a intencionalidade, o resultado, a mediação docente, a mobilização e significação dos conteúdos apreendidos pelos discentes.

Nesta pesquisa, verificamos que os docentes têm empregado em suas atividades, diferentes estratégias de ensino, conforme apresentado na tabela abaixo, os dados apresentados referem-se a respostas múltiplas de 07 docentes:

Tabela 1 - Distribuição das estratégias de ensino referidas pelos docentes investigados. Caruaru - PE, 2017.

\begin{tabular}{ccc}
\hline Estratégias Utilizadas & N & Percentil (\%) \\
\hline Aula Expositiva & 06 & $86 \%$ \\
Estudo de Caso & 06 & $86 \%$ \\
Simulação & 04 & $57 \%$ \\
Seminários & 03 & $43 \%$ \\
Debate & 02 & $28 \%$ \\
Cartilha & 01 & $14 \%$ \\
Grupo Verbaliza/Grupo Observa & 01 & $14 \%$ \\
Jogos Educativos & 01 & $14 \%$ \\
Roda de Conversa & 01 & $14 \%$ \\
Dramatização & 01 & $14 \%$ \\
\hline
\end{tabular}

Fonte: OLIVEIRA; RODRIGUES E FREITAS, 2017.

Lazzari et al., (2011) ressaltam a importância de utilizar diversas metodologias ativas da aprendizagem, uma vez que a aprendizagem não é uniforme e, portanto, para a seleção e aplicação das estratégias a serem efetivadas, deve o docente considerar a singularidade do aluno, o modo de aprendizagem de cada um, e o objeto de apreensão. 
Nas falas dos docentes observamos que a aula expositiva, o estudo de caso e a simulação são algumas das estratégias utilizadas na formação em enfermagem, como demonstrado abaixo:

\begin{abstract}
"Costumo trabalhar sempre associando a parte prática com a parte teórica, então muitas das aulas, a gente consegue vivenciar em laboratórios com práticas de simulações realistas. Procuro utilizar maneiras pedagógicas diferentes, para poder não trabalhar com a repetição e monotonia, mas tentar absorver do aluno aquilo que ele pode oferecer, tento construir uma proposta para nivelar os alunos de uma maneira bem uniforme. 0 máximo que eu posso está é atuando com a parte prática envolvendo a teoria e fazendo esse aluno a ser um sujeito inquieto, crítico, absorvendo também informações que ele traz de sua cultura, de seus costumes para que a gente consiga construir e reconstruir os saberes que são partilhados" (D1).
\end{abstract}

"Uma das mais utilizadas é a aula expositiva dialogada, além da aula expositiva dialogada, utilizo muito roda de conversa e também discussão de casos para que o aluno possa está relatando as experiências e também explanar aquilo que sabe, de acordo com a temática que é abordada em sala de aula" (D2).

"Geralmente eu utilizo a aula expositiva que infelizmente a gente não consegue se desprender totalmente dela, né? Apesar de saber que não é uma das formas mais adequadas, então me eu utilizo dessa estratégia expositiva. Trago bastante estudo de caso, a maior parte dos exercícios que eu faço inclui estudo de caso, no sentido de aproximar com a realidade e fazer com que ele de fato compreenda o conteúdo e saiba aplicar na prática" (D4).

Nos depoimentos, verificamos a preocupação de alguns docentes em tornar a aula atrativa, apresentando os conteúdos de diferentes formas. Todavia, também é notório o conservadorismo de alguns professores, no que concerne a exposição dos conteúdos e o enfoque técnico das atividades de enfermagem. De certo, uma das habilidades do profissional de enfermagem envolve o conhecimento e a efetivação de procedimentos em saúde; porém, estes não se restringem a mera execução de tarefas, uma vez que considera a complexidade do cuidar e os atores nela envolvidos (LAZZARI et al., 2011).

Evidenciamos uma maior tendência às estratégias tradicionais mencionadas nos discursos:

\begin{abstract}
"Desenvolvo aula expositiva, geralmente a aula expositiva é o que os nossos alunos mais querem né? Eles não querem aulas voltadas para eles irem em busca, eles geralmente querem aquela aula que o professor bote slide cheio de texto e nesses slides cheios de textos eles vão usar para estudar para prova, então para se adequar um pouco eu também uso aulas expositiva com slide e, isso termina sendo uma coisa que as vezes se torna até metade da minha disciplina, sendo só desse tipo de aula (D5)".
\end{abstract}


"Como a minha disciplina é muito prática, eu tento sempre inserir a teoria vinculada à prática, geralmente eu articulo teoria e prática. Eu sempre faço ou aula expositiva com demonstração de dispositivos, equipamentos em sala de aula ou a aula teórica ou prática já em laboratório (D7)".

Os métodos de exposição verbal dos conteúdos e técnicas exigem do discente uma postura passiva, receptiva e mecânica. De acordo com Berbel (2011) esse tipo de ensino não promove apropriação da aprendizagem, pois coloca o aluno na qualidade de expectador do mundo, sem senso de responsabilidade com a realidade em que se insere.

Observamos que o participante D2 expressa em seu discurso o uso da aula expositiva dialogada, diferentemente da aula expositiva tradicional, permitindo a participação do aluno que tem suas opiniões e observações consideradas.

Depreende-se da maioria das falas o uso dos estudos de caso e/ou discussão de casos clínicos como estratégias privilegiadas na formação dos estudantes de enfermagem. Trata-se de estratégias problematizadoras que viabilizam a articulação entre teoria e prática numa perspectiva interdisciplinar. A utilização deste tipo de metodologia na formação em saúde tem se expandindo em virtude de sua adequação a conjuntura educativa deste campo de atuação, uma vez que propicia o processo de reflexão e tomada de decisão (SILVA et al., 2014).

Referente à execução de atividades práticas em laboratórios (simulação), 57\% (n=04) dos docentes, pontuou utilizar essa estratégia como forma de consolidar os conhecimentos produzidos mediante o aporte teórico estudado. Segundo Costa et al., (2015) a simulação é uma metodologia ativa que permite aos estudantes a oportunidade de experimentar a representação de uma situação real, com o intuito de aprender, praticar, refletir, intervir e avaliar o contexto vivenciado.

Neste sentido, o uso da simulação na educação em enfermagem, não pode estar condicionado apenas ao treinamento e execução de técnicas em saúde; deve considerar o cenário que envolve o contexto do cuidar, uma vez que a prática em enfermagem não se limita a execução de procedimentos, conforme implícito na fala de um dos docentes:

"Outra técnica que utilizo também é o recurso prático nos laboratórios, a depender do conteúdo, quando a gente pode alinhar a parte teórica com a parte prática" (D4). 
Conforme Souza e Bezerra (2013), para que exista uma aprendizagem ativa é necessário que os professores adotem posturas ativas, promovendo um ambiente favorável a aprendizagem onde a colaboração, a criatividade, o incentivo para a resolução de problemas e a interdisciplinaridade, sejam capazes de promover processos de pensamento crítico e de alto nível, fundamentados na realidade. O desenvolvimento de ambientes com essas características instiga a autonomia do discente, o pensamento reflexivo, investigativo e o motiva para construir e significar o conhecimento.

\section{3ํㅡㄹ Categoria: Estratégias de Aprendizagem e Percepções sobre a Prática}

No intuito de investigar a percepção dos docentes sobre as estratégias que utilizam em sua prática foi perguntado aos participantes deste estudo quais estratégias consideravam gerar maior aprendizagem dos discentes e quais acreditavam não gerar resultados positivos.

No que concerne às estratégias, consideradas importantes e profícuas na construção da aprendizagem dos discentes de enfermagem, os docentes destacaram as seguintes estratégias: estudo de caso e/ou caso clínico representando $43 \%$ (n=03), simulação realística 29\% (n=02), seguido de dramatização 14\% (n=01) e seminário 14\% (n=01).

Os docentes acreditam que as estratégias acima citadas propiciam um ensino pautado em circunstâncias reais, contextualizado e participativo, como demonstram as falas:

\footnotetext{
"A gente da área de saúde se trouxer somente aquilo que é teórico, estamos reproduzindo os autores e livros, eu posso não conseguir alcançar e preparar esse aluno para vivência real" (D1).

"Uma das estratégias que eu também gosto bastante é a estratégia problematizadora, sempre procuro trazer um problema relacionado aquele tema, é como se aproximasse mais da realidade, atraísse mais atenção do aluno e fizesse com que ele também tivesse um aspecto participativo maior" (D4).

"Quando a gente faz a discussão prévia e eles fazem isso na prática, eles aprendem muito mais porque eles praticam" (D7).
}

A execução das estratégias mencionadas pelos participantes deste estudo, na formação em enfermagem corrobora com a pesquisa realizada por Waterkemper e Prado (2011) quando estes afirmam que no Brasil as estratégias de ensino consideradas 
estimuladoras do pensamento crítico e reflexivo no ensino em enfermagem, evidenciadas pela literatura, são: estudo de caso, simulações e dramatizações.

Quanto às estratégias que podem promover resultados precários na formação em enfermagem, a maioria dos participantes apontou o seminário como estratégia pouco efetiva $43 \%$ ( $n=03$ ), seguido de aula expositiva dialogada 29\% ( $n=02)$ e utilização de vídeos $14 \%(n=01)$, $14 \%(n=01)$ ignorou esta pergunta.

Sobre os seminários foi alegado:

“[...] De todas as opções aquela que eu percebi que foi menos factível foi a estratégia dos seminários. Talvez os alunos não conseguem compreender a proposta de um seminário [...]" (D1).

“[...] Ao final desse tipo de apresentação os participantes do seminário aprendem bastante sobre o tema, o que é bem contrastante com o restante da turma que durante o seminário eles estão mais preocupados em está somente presente, do que realmente aprender" (D5).

“[...] Eu utilizo na minha prática ainda os seminários, mas eu acredito que diante do perfil de aluno que nós temos hoje é um recurso que não tenho tanto resultado quanto às demais estratégias. [...] Acaba sendo um trabalho superficial e meio que mecânico, porque geralmente a gente trabalha seminário em grupo e os alunos tem a tendência de fazer divisões, acaba se tendo uma fragmentação da pesquisa" (D7).

De acordo com Marcheti (2001) e Anastasiou e Alves (2005) a estratégia de aprendizagem denominada Seminário permite um debate de temáticas ou problemas que instigam a criatividade, a independência e o desenvolvimento do intelecto do aluno. Para Marcheti (2001) o sucesso da estratégia depende da responsabilidade dos envolvidos professor e alunos, onde cabe ao professor, como organizador do processo, conduzir a proposta, indicando aos estudantes como o Seminário deverá ser organizado para que a fragmentação de conteúdos não aconteça.

Nas falas pronunciadas, podemos observar a atribuição do insucesso dos seminários à compreensão insatisfatória desta proposta de aprendizagem pelo aluno, a ausência do desejo de compreender o trabalho dos outros colegas de sala de aula, bem como a fragmentação do conteúdo a ser apresentado pelo grupo. 
Embora $43 \%$ dos docentes investigados tenham declarado que a estratégia de Seminário não apresenta um resultado promissor, em outro momento nesta pesquisa esta estratégia aparece como uma das mais utilizadas, conforme explanado em momento anterior. Isto demonstra uma contradição da própria prática, uma vez que os docentes não a consideram interessante, entretanto, continuam a utilizá-la.

De fato, a passividade dos discentes é um problema para a execução de qualquer metodologia ativa da aprendizagem, cabendo ao professor instiga-los e motivá-los para que se reconheçam como sujeitos do processo de aprendizagem.

Sobre a compreensão inadequada e a fragmentação dos estudos referidos pelos professores, ressaltamos mais uma vez a reflexão constante da prática docente. No tocante aos seminários é pertinente que o docente se posicione de maneira apropriada (fazendo com que o que se pede seja compreendido), orientando, desafiando, favorecendo diálogo, explanando os critérios de avaliação, realizando síntese integradora ao término de cada seminário desenvolvido, alcançado os objetivos propostos (MARCHETI, 2001).

A aprendizagem pode ocorrer em diferentes ambientes, circunstâncias e formas, a aula expositiva dialogada e a utilização de vídeos, assim como as diversas estratégias existentes podem ser incorporadas ao processo de ensino em saúde. Porém, cabe ao docente refletir sobre a melhor forma de utilizar cada uma delas, sempre observando quais habilidades intelectuais e cognitivas deverão ser alcançadas.

\section{CONSIDERAÇÕES FINAIS}

Considerando as competências e habilidades indicadas nas Diretrizes Curriculares Nacionais (DCN) para o curso de enfermagem, com vistas à utilização de metodologias de ensino e aprendizagem para formação de profissionais críticos, reflexivos e comprometidos com as questões sociais, observamos que os participantes desta pesquisa estão preocupados com o ensino reflexivo e significativo na formação de enfermeiros. Além disso, pontuaram a importância da autonomia dos discentes e a mediação da aprendizagem na relação pedagógica entre professor e aluno. 
No que concerne às estratégias de ensino, os docentes alegaram utilizar métodos diversos, sendo os mais comuns na formação em enfermagem: simulação, aula expositiva dialogada e os estudos de casos.

Os docentes que participaram desta pesquisa compreendem a importância do uso de métodos ativos de ensino e aprendizagem; entretanto, a aplicabilidade de tais métodos na prática pedagógica ainda se encontra fragilizada o que indica a possibilidade de novas pesquisas.

As fragilidades foram perceptíveis, uma vez que por meio das entrevistas identificamos em alguns momentos, discursos conservadores e que são condizentes com as práticas tradicionais de ensino, principalmente no que concerne à seleção das atividades e avaliação quando estes métodos são utilizados.

Nesta vertente, ratificamos que a relação pedagógica deve ser um campo constante de reflexão, uma vez que esta atitude reflexiva pode ser capaz de modificar o cenário educacional do ensino no campo da enfermagem, marcado pelo conservadorismo no que diz respeito aos processos de ensinar e aprender. Assim, somente a identificação e tomada de decisão frente aos obstáculos encontrados nas atividades docentes é capaz de remodelar a prática de ensino em enfermagem, avançando para uma perspectiva educativa significativa e transformadora.

Existe a indicação do quão profícuo é criar espaços de reflexão docente na educação superior em enfermagem, com a intenção de provocar e modificar a prática dos professores que desenvolvem suas atividades neste nível de ensino. A formação permanente destes profissionais no âmbito das IES pode ser o caminho para a almejada mudança, condizente com a conjuntura educacional atual.

Além disso, há a necessidade da promoção da reflexividade discente, na intenção deste se reconhecer-se enquanto sujeito de sua aprendizagem, se mobilizando, desenvolvendo autonomia e a cognição por intermédio da mediação docente.

Enseja-se que novos estudos possam emergir, no intuito de continuar com as investigações acerca da temática que contempla este estudo, envolvendo docentes, discentes, serviços de saúde, Instituições Superiores de Ensino e todos aqueles que almejam colaborar para a formação de profissionais científicos, éticos e humanísticos no âmbito da enfermagem. 


\section{Oliveira et al.}

\section{REFERÊNCIAS}

ABREU, Rute M.L. Estratégias de Ensino Aprendizagem no Contexto do Curso de Graduação em Enfermagem. 2014. Dissertação (Mestrado profissional em Ensino na Saúde). Faculdade de Medicina da Universidade Federal de Alagoas, Maceió, 2014.

ANASTASIOU, Lea G. C.; ALVES, Leonir P. Estratégias de ensinagem. ln: Anastasiou, L.G.C; Alves, L. P. Processos de ensinagem na universidade: pressupostos para as estratégias de trabalho em aula.5ed.Joenville: SC. Unlville, 2005.Cap.3

BRASIL. Ministério da Educação e Cultura. RESOLUÇÃo CNE/CES № 3, DE 7 DE NOVEMBRO DE 2001: Institui Diretrizes Curriculares Nacionais do Curso de Graduação em Enfermagem. Disponível em <http://portal.mec.gov.br/cne/arquivos/pdf/CES03.pdf> Acesso em 20/03/2016.

BERBEL, Neuzi A. N. As metodologias Ativas e a da Autonomia de Estudantes. Semina: Ciências sociais e humanas, Londrina, v. 32, n.1, p. 25-40, 2011.

CECCIM, Ricardo B; FEUERWERKER, Laura C.M. O quadrilátero da formação para a área da saúde: Ensino. Gestão, Atenção e Controle social. PHYSIS: Revista Saúde Coletiva, Rio de Janeiro, V.14, n.1, p.41-64, 2004. Disponível em < http://www.scielo.br/pdf/physis/v14n1/v14n1a04.pdf > Acesso em: 28.04.2016.

CHARLOT, Bernard. Da relação com o saber: elementos para uma teoria. Porto Alegre: Artmed Editora, 2000.

COSTA, Raphael R.O. et al. O uso da simulação no contexto da educação e formação em saúde e enfermagem: uma reflexão acadêmica. Revista espaço para a saúde, Londrina, v. 16, n. 1, p. 59-65, 2015.

FREIRE, Paulo. Pedagogia da autonomia: saberes necessários à prática educativa. 33ª ed. São Paulo: Paz e Terra, 2006.

FERNANDEZ, Alicia. Os Idiomas do Aprendente. São Paulo: Editora Artmed, 2001.

LAZZARI, Daniele D. et al. Estratégias de Ensino do Cuidado de Enfermagem: um olhar sobre as tendências pedagógicas. Revista Gaúcha de Enfermagem, Porto Alegre, n.32, v.4, p.688-94, 2011.

LEITÃo, Selma. Argumentação e desenvolvimento do pensamento reflexivo. Psicologia: Reflexão e Crítica, Porto Alegre, v.20, n.3, p. 454-462, 2007. Disponível em < http://www.scielo.br/scielo.php?script=sci_arttext\&pid=S0102-79722007000300013> Acesso em: 01.05.2017.

LIBÂNEO, José C. Democratização da escola pública: A pedagogia crítico social dos conteúdos. 23 ed. São Paulo: Loyola, 2009.

LUCCHESE, Roselma; VERA, Ivânia; PEREIRA, Wilza R. As políticas públicas de saúde - SUS - como referência para o processo ensino-aprendizagem do enfermeiro. Revista Eletrônica de Enfermagem, v. 12, n.3, p.562-6, 2010. Disponível em < https://www.fen.ufg.br/revista/v12/n3/v12n3a21.htm> Acesso em 12.06.2017.

MARCHETI, Ana P.C. Aula expositiva, seminários e projeto no ensino de engenharia: Um estudo exploratório utilizando a teoria das inteligências múltiplas. 2001. Dissertação (Mestrado em engenharia de produção) - Escola de Engenharia de São Carlos da Universidade de São Paulo, São Paulo, 2001.

MELO, Tiago O. et al. O olhar do docente acerca dos alunos que trabalham inseridos nas metodologias ativas da aprendizagem. Revista da Faculdade Ciências Médicas de Sorocaba, Sorocaba, v.16, n.3, p.134-138, 2014.

MENEGAZ, Jouhanna C. Práticas do bom professor de enfermagem, medicina e odontologia na percepção de estudantes. 2012. 169f. Dissertação (Mestrado em Enfermagem). Programa de Pós-Graduação em Enfermagem. Universidade Federal de Santa Catarina, Florianópolis,2012. 
MESQUITA, Simone K.C. Abordagens pedagógicas na formação de enfermeiros: compreensão de docentes de enfermagem. 2012. Dissertação (Mestrado em enfermagem) - Universidade Federal do Rio Grande do Norte, Natal, 2012.

MINAYO, Maria C. S. (Org.). Pesquisa social: teoria, método e criatividade. Petrópolis: Vozes, 2001.

MITRE, Sandra M. et al. Metodologias ativas de ensino-aprendizagem na formação profissional em saúde: debates atuais. Ciência e Saúde Coletiva, Rio de Janeiro, v.13, n.2, p.2133-2144, 2008.

PARANHOS, Vania D; MENDES, Maria M.R. Currículo por competência e metodologia ativa: percepção de estudantes de enfermagem. Revista Latino Americana de Enfermagem, Brasília, v.18, n.1, 2010. Disponível em < http://www.scielo.br/pdf/rlae/v18n1/pt_17.pdf> Acesso em: 06.01.2017.

SEVERO, Ivan R.M.; KASSEBOEHMER, Ana C. Motivação dos alunos: reflexões sobre o perfil motivacional e a percepção dos professores. Ensino de Química em foco, São Paulo, v.39, n. 1 p,75-82, 2017. Disponível em <http://qnesc.sbq.org.br/online/qnesc39_1/12-EQF-89-15.pdf> Acesso em: 01.05.2017.

SILVA, Rudval S. et al. Estudo de caso como uma estratégia de ensino na graduação:

Percepção dos graduandos em enfermagem. Revista Cuidarte, Colômbia, v. 5, n. 1, p. 606-612, 2014. Disponível em < http://www.scielo.org.co/scielo.php?pid=S2216-09732014000100004\&script=sci_abstract\&tlng=pt> Acesso em: 15.07.2017.

SOUZA, Francislê N; BEZERRA, Anna C. Do ensino ativo à aprendizagem ativa: o papel da investigação na formação do professor do futuro. Revista de Investigación Universitaria, v.2, n.1, p.11-26, 2013.

SOUZA, Alba R.B; SARTORIB, Ademilde S; ROESLERC, Jucimara. Mediação pedagógica na educação a distância: entre enunciados teóricos e práticas construídas. Revista Diálogo Educação, Curitiba, v. 8, n. 24, p. 327-339, 2008.

WATERKEMPER, Roberta; PRADO, Marta L. Estratégias de ensino-aprendizagem em cursos de graduação em Enfermagem. Av.enferm., Bogotá , v. 29, n. 2, p. 234-246, 2011. Disponível em <http://www.scielo.org.co/scielo.php?script=sci_arttext\&pid=S0121-45002011000200003\&lng=pt\&nrm=iso>. Acesso em: 08.06. 2017.

\section{(cc) B $\mathrm{BY}$}

Este trabalho está licenciado com uma Licença Creative Commons - Atribuição 4.0 Internacional. 